\title{
Disciplinary action for academic dishonesty: does the student's gender matter?
}

Hope Witmer ${ }^{1}$ and Jonas Johansson ${ }^{2^{*}}$

\author{
* Correspondence: \\ jonas.johansson@ftf.lth.se \\ ${ }^{2}$ Solid State Physics and the \\ Nanometer Structure Consortium, \\ Lund University, Box 118, SE-22100 \\ Lund, Sweden \\ Full list of author information is \\ available at the end of the article
}

\begin{abstract}
The purpose of this study is to identify if gender differences exist with respect to conviction of university students for academic dishonesty. To investigate this phenomenon, data from the Swedish National Agency for Higher Education (SNAHE) and from disciplinary boards of several Swedish universities were evaluated from a gender perspective. To identify whether the penalty severity for academic dishonesty is gender biased, the ratio of suspensions/warnings for male and female students was calculated. It was identified that female students are less prevalent in disciplinary matters and that there was no systematic gender bias in penalty severities (warnings or suspensions). In addition, female students deny academic dishonest behaviors more than male students, indicating a possibly higher false conviction rate.
\end{abstract}

Keywords: Gender; Academic dishonesty; Cheating; Disciplinary action

\section{Springer}

\section{Introduction}

Academic dishonesty in higher education, such as cheating and plagiarism, is a growing problem and the number of reported cases continues to increase (Edgren \& Walters 2006; Magnus et al. 2002; Trost 2009). Cheating and other acts of academic dishonesty are a growing concern because they threaten the integrity of the learning process and could potentially undermine the credibility of educational programs. The introduction of easy accessibility to electronic media and lack of standard practices has added increasing levels of complexity to this issue (Awdry, \& Sarre, 2013; Colnerud \& Rosander, 2009; Glendinning 2014; McCabe 2005). Furthermore, there are distinctions of intentionality and consciousness in academic dishonesty acts that range on a continuum from conscious and deliberate to ignorant deception (Colnerud \& Rosander, 2009). The majority of the research done on academic dishonesty has mainly been generated from the UK, North America and Australia (Glendinning 2014). In 2009 the Impact of Policies for Plagiarism in Higher Education across Europe (IPPHEAE) was developed to "investigate how student plagiarism was being addressed in Higher Education institutions (HEIs) throughout 27 countries of the European Union (EU)" (Glendinning 2014:5). Sweden was ranked number $3(19.22 / 36)$ out of 27 countries according to the academic maturity model that measures areas such as research, training, prevention and policies for academic misconduct (Glendinning 2013:35). Sweden's strength is partially attributed to having both a national system for

(c) 2015 Witmer and Johansson. This is an Open Access article distributed under the terms of the Creative Commons Attribution License (http://creativecommons.org/licenses/by/4.0), which permits unrestricted use, distribution, and reproduction in any medium, provided the original work is properly credited. 
collecting data annually from universities about academic misconduct and nationally prescribed policies for handling these issues (Glendinning 2013:35).

Disciplinary governance structure and academic dishonesty in Sweden

In Sweden, Universitetskanslerämbetet (UKÄ) (formerly Högskoleverket [HSV], the Swedish National Agency for Higher Education) is the public authority that oversees higher education institutions (HEI). UKÄ requires that each HEI appoint a disciplinary board to assess disciplinary cases and determine sentences (HSV 2005). The disciplinary boards are then required to report data on all disciplinary actions to the UKÄ. Included in these reports is information regarding severity of sentencing and gender (Trost 2009; HSV 2005). According to the HSV data the number of disciplinary board sentences from 2001 to 2010 has increased significantly (HSV 2011). The behaviors included in academic misconduct, listed from lesser to greater offenses, are as follows: cheat sheets, unauthorized collaboration, plagiarism, forging documents, disruptive behavior, and sexual or ethnic harassment (Trost 2009). The most frequently reported form of academic misconduct was plagiarism and fabrication, and the least was sexual/ ethnic harassment (HSV 2005; HSV 2011). The first three categories (cheating, unauthorized collaboration, and plagiarism and fabrication) are officially the main categories for academic dishonesty in Sweden (Colnerud \& Rosander, 2009). Trost (2009) study on academic dishonesty in Sweden identified that academic dishonesty is highly prevalent in the Swedish university system. However, very few students are actually involved (0.1 \% in 2004) in academic disciplinary cases (Colnerud \& Rosander, 2009). It is important to note that although governance and reporting structures can track and report this behavior, disciplinary activities are subjective, contingent on the opinions and judgment of faculty or other members of the academic institution (Robinson-Zañartu et al. 2005).

\section{Review of literature}

\section{Cheating and the role of faculty}

Two significant contextual and institutional factors that impact cheating behavior are the severity of penalty and the role of faculty (Hughes \& McCabe 2006). Typically the onus for cheating is placed primarily on the student with little exploration of the impact of the faculty's contribution to the cheating behavior. Faculty are frequently viewed as the protagonists who are rewarded for reporting academic dishonesty and students the antagonists who are punished for their behavior (Parameswaran 2007). McCabe (2005) assessment of almost 10,000 faculty members from 2002 to 2004 showed that $44 \%$ of those who were aware that their students engaged in cheating over that time period had never reported a student for cheating to the appropriate campus authority. According to a study based on 842 faculty members' perceptions of responses to plagiarism, perceptions of severity of the offense strongly mediated the consequence that they recommend (Robinson-Zañartu et al. 2005).

\section{Gender and academic dishonesty}

Much of the research on self-reported academic dishonesty identifies that female students cheat less than their male counterparts. This has been summarized in two meta- 
analyses by Whitley et al. (1999) and Athanasou and Olasehinde (2002). However, there remains a slight lack of consensus on this issue. In Leming (1980) report, women cheat significantly more than men under low risk conditions. In this investigation, a test was administered under two different conditions: in one test stern warnings were issued against cheating and professors checked the test subjects carefully all the time (high risk condition); in the other test, no warnings were given and the instructor read a magazine and only occasionally looked up at the test subjects (low risk condition). Leming found that all subjects, both males and females, cheated more under the low risk condition. This naturally led to the conclusion that cheating is situation specific. In addition, under low risk conditions, women were found to cheat significantly more than men. This was reported as a surprising observation and was discussed in terms of the notion that threats of sanction have a higher impact on women than on men (Tittle \& Rowe 1973). Still, this does not indicate conclusively that women cheat more than men. It only explains that there is a significant discrepancy between male and female cheating frequencies under low risk conditions.

In contrast to this, Nonis and Swift (2001) concluded that academic dishonesty is not situation specific, but instead linked to the students' individual attitudes. Nonis and Swift collected data about academic dishonesty from a large sample of business students, both undergraduates and graduates, in the form of a questionnaire. One part of the questionnaire addressed issues of workplace related dishonesty and was supposed to be answered only by those who had or have had a part-time job during their studies. According to their results, academic and workplace dishonesty are strongly correlated. This led to the conclusion that acts of dishonesty such as cheating and plagiarism are not situation specific but linked to personal attitudes: "Once an individual forms the attitude that it is acceptable behavior, he or she is likely to use this behavior, not only in the educational arena but also in other arenas" (Nonis \& Swift 2001). They also found that academic dishonesty is more widespread among males and younger students. These subgroups were also more tolerant of dishonest behavior in the workplace.

The observation that females are less tolerant to academic dishonesty is further supported by the investigation of Ameen et al. (1996), where accounting students answered survey questions about unethical behavior that they were expected to be familiar with, either by having observed such activities or by having engaged in them. In this investigation it was found that female students are less tolerant to unethical behavior, are less cynical, and are less likely to engage in acts of academic dishonesty than male students. Other studies support this position that students with moral beliefs are less likely to engage in academic dishonesty, for example Gibson et al. (2008). This could also be attributed to the student's individual interpretation of the degree of severity of the act and if, based on their logic and attitudes, the behaviour even qualifies as academic dishonesty (Colnerud \& Rosander, 2009).

\section{Gender and sentencing decisions}

Here we also raise the question: Does the decision-maker's gender impact the sentencing outcome? To further understand this question, two other studies will be referenced. The first study compared the sentencing decisions of male and female judges, and the second study addressed the evaluation of female faculty members' perceptions 
of and response to plagiarism. The purpose of the first study was to assess whether male and female judges impose similar sentences on criminal defendants and whether they use the same criteria and give the same weight to characteristics of a case when arriving at a decision. The results indicate many similarities but some differences between male and female sentencing practices. Female judges are somewhat harsher as indicated by an increased likelihood to incarcerate and impose longer sentences. When assessing the verdict, they tend toward a more contextualized style in weighing the effects of defendant characteristics and prior record on sentencing (Steffensmeier \& Hebert 1999).

A similar study was conducted to evaluate academic discipline in relationship to faculty members' perceptions and responses to plagiarism. This study identified that female faculty members were $36 \%$ more likely to judge cases more severely than their male counterparts. It also indicated that the gender bias this infers was trivial compared to the frequency and use of the plagiarism material. Neither of the studies mentioned in this section differentiated if the severity of judgment was different for men or women. What the studies did indicate is that women imposed harsher sentences and judged more severely than men (RobinsonRobinson-Zañartu et al. 2005).

\section{Aim and purpose}

The research in this paper explores if the consequences assigned by faculty for academic dishonesty are influenced by gender bias. It has been previously documented that women are judged more harshly than men in teaching evaluations (Sprague \& Massoni 2005); however, the question regarding whether female students are judged by faculty more harshly than male students for academic dishonesty has not been explored. To investigate this, we analyzed gender aspects of academic dishonesty based on data from disciplinary boards of several Swedish universities.

The aim of this study is to introduce a gender perspective to this discourse by exploring if the student's gender matters to the individuals that are assigning the discipline for academic dishonesty. Statistics from Sweden, a country that has a centralized database and specific mandates for reporting disciplinary action for academic misconduct, will be the focus of this study. We are not aware of any previous investigation where gender aspects of academic dishonesty have been studied based on the combination of disciplinary board protocols and statistics of convicted students in the Swedish context. The advantage with this approach is that we analyze real cases and we can perform analysis (although rudimentary) of the protocols. The disadvantage is that we see only the tip of the iceberg, since we lack information on the probably vast amount of unrecorded and undiscovered cases of academic dishonesty.

\section{Method}

The Swedish National Agency for Higher Education (SNAHE) publishes annual reports with statistics on the disciplinary cases at Swedish universities. As a basis for our research we used the report from 2010. The numbers of male and female students that were convicted were listed for each university and the fraction of convicted students were in the range of 0.03 to $0.39 \%$ (HSV 2011). However, no information about the gender of the warned and suspended students was listed. Since this point is important for our research we asked 10 of the 30 listed Swedish universities to provide this 
information. Among the selected universities are both large research-oriented universities and smaller, more exam-oriented, university colleges. We believe that they represent a cross-section of the Swedish higher education and all of the selected universities had a fraction of convicted students in the range of 0.07 to $0.23 \%$. Eight of the requested universities responded and we received a variety of answers. Some universities sent us all the disciplinary board protocols and decisions; some gave us the same summary of cases as they sent to the SNAHE, and two just gave us the requested numbers and no additional information.

Since the disciplinary board protocols include statements from the accused students we have carried out an analysis where we categorize the students' statements and analyze the results with respect to gender.

\section{Results}

According to the SNAHE data on full-time university students that are subject to disciplinary action, the number of disciplinary board sentences from 2001 to 2013 has increased significantly (see Fig. 1). The report from 2005 indicates that there was a $227 \%$ increase of discipline cases from 2001 to 2005 . The range went from 127 reported cases in 2001 to 415 cases reported in 2005 (HSV 2005). According to the report from 2010 (HSV 2011), 705 students were subject to disciplinary action that year. This corresponds to an increase of $48 \%$ from 2009. The most common reason for disciplinary action for the last ten years (at least) is plagiarism (HSV 2011). During 2010, $0.23 \%$ of the full-time students at Swedish universities were subject to disciplinary action (HSV 2011).

According to the Swedish statistics from 2010, women were less prevalent in disciplinary matters, which could indicate that women are less prone to academic dishonesty or are convicted less frequently. According to these same statistics $59 \%$ of all the fulltime students are women while only $42 \%$ of the students with disciplinary sentences are women. However, in the most recent report from UKÄ, describing the statistics from 2013, the numbers have turned (UKÄ 2014): while female students are still in the

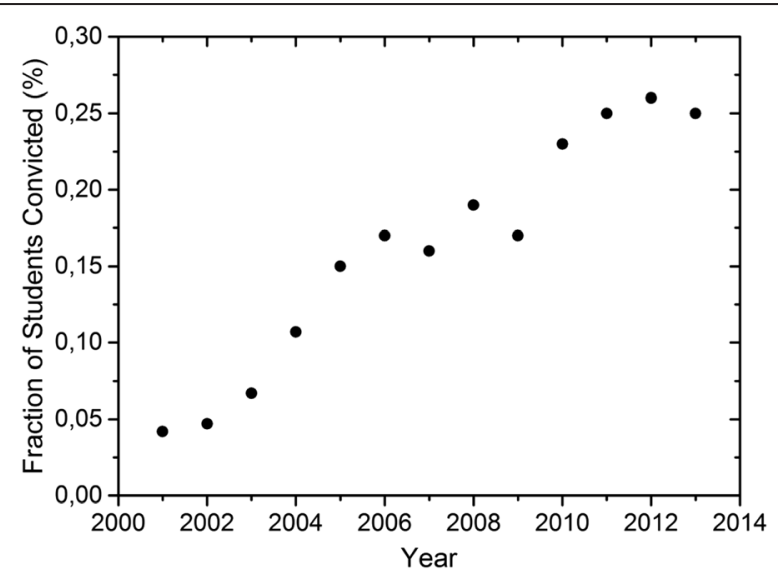

Fig. 1 The fraction of full-time university students in Sweden who were subject to disciplinary action from 2001 to 2013. The data from 2001 to 2004 are extracted from HSV 2005 report (2005), the data from 2005 to 2010 from HSV 2011 report (2011), the data from 2011 from UKÄ 2013 report (2013) and the data from 2012 and 2013 from UKÄ 2014 report (2014). The graph shows that the fraction of students that were convicted for academic misconduct follows an increasing trend, from $0.04 \%$ in 2001 to $0.25 \%$ in 2013 
majority (59\% of full-time students), $51 \%$ of the convicted students are women. So among the convicted students, the women outnumber the men. However, the fraction of female students that are convicted is still smaller than the fraction of male students that are convicted.

In order to find out whether the penalty severity for academic dishonesty is gender biased, we have calculated the ratio of suspensions/warnings for male and female students. Among the investigated Swedish universities we see no trend in this ratio. In some universities female students have a higher ratio and in some universities male students have a higher ratio.

Finally, we categorize disciplinary board protocols by dividing the accused students' responses into three categories: (i) did not understand the rules, (ii) denies intent to cheat, and (iii) admits to cheating. Results from three Swedish universities are summarized in Table 1 and Fig. 2. This data indicates that female students are underrepresented in category (iii), which could mean that female students claim that they have not understood the rules or deny intent to cheat more often than male students. Since the possibly not guilty students are to be found in categories (i) and (ii), this finding could suggest that female students are at higher risk than male students of being falsely convicted or that someone in category (iii) is not guilty but has falsely confessed.

The careful scrutiny of the protocols from the same disciplinary board also revealed a couple of interesting cases. A female and a male student were convicted by the disciplinary board for the same dishonest behavior (using course summary notes prepared by fellow students as unauthorized help during a home exam). Here the male student was given no discipline and the female student was suspended for the same infraction. This particular case appears to be in stark contrast to the implications indicated previously that gender bias does not influence the severity of the penalty. However, we are not aware of mitigating circumstances that the disciplinary boards are obliged to consider (e.g., information given by teachers, length of study time, e.g.,) that could have contributed to the different punishments for their actions.

In another case, a female student was found guilty of plagiarism and was sentenced to a two week summer suspension. In comparison to the average suspension period of about six weeks reported in HSV (2005); HSV 2006), this is a comparatively short time period.

\section{Discussion}

In the present study it was found that during 2010 only $0.23 \%$ of full-time students at Swedish universities were subject to disciplinary action (HSV 2005, HSV 2011). This is

Table 1 Categorization of sentenced students' responses in disciplinary board protocols from three Swedish universities, here denoted as A, B, and C

\begin{tabular}{|c|c|c|c|c|c|c|}
\hline \multirow[t]{2}{*}{ Category of student responses } & \multicolumn{2}{|c|}{ University A } & \multicolumn{2}{|c|}{ University B } & \multicolumn{2}{|c|}{ University C } \\
\hline & $F(\%)$ & $M(\%)$ & $F(\%)$ & $M(\%)$ & $F(\%)$ & $M(\%)$ \\
\hline (i) Did not understand the rules & 9 & 13 & 25 & 0 & 60 & 22 \\
\hline (ii) Denies intent to cheat & 73 & 53 & 50 & 70 & 40 & 22 \\
\hline (iii) Admits to cheating & 18 & 34 & 25 & 30 & 0 & 56 \\
\hline
\end{tabular}

The fraction of female students is denoted by $F$ and the fraction of male students by $M$. At university $A, 11$ female and 15 male students were sentenced. The corresponding numbers for university $B$ and $C$ are 4 females, 10 males, and 5 females, 9 males, respectively 


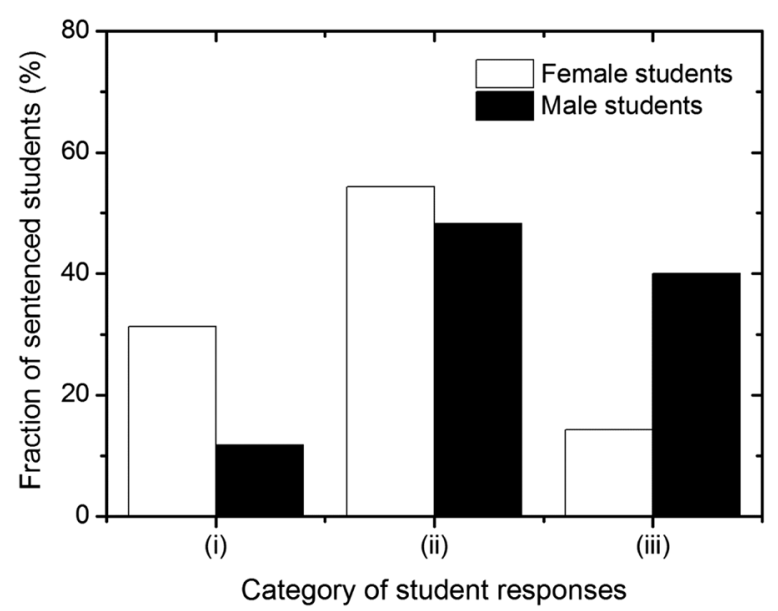

Fig. 2 Gender categorization of sentenced students' responses in disciplinary board protocols from three Swedish universities: $\mathbf{i}$ did not understand the rules, ii denies intent to cheat, iii admits to cheating. Female students are overrepresented in category (i) and (ii) and underrepresented in category (iii). Since the possibly not guilty students are to be found in categories (i) and (ii), this finding suggests that possibly female students are at a higher risk than male students of being falsely convicted or that someone in category (iii) is not guilty but has falsely confessed

quite a small fraction when compared to the 60 to $70 \%$ of students (Whitley et al. 1999; Athanasou and Olasehinde 2002) who typically admit to cheating in self-reports. This could indicate that there is a high fraction of unrecorded cases of academic dishonesty. However, that is a rather simplistic conclusion, without considering other factors such as the type of offense, the reporting policies and practices and the cultural context. For example the low percentage of reported incidents could be attributed to what Trost (2009) purports as the Swedish shared societal value of honesty that is linked to national identity. Another explanation could be that the low level of reporting is due to acts of conscious deception, self-deception or ignorant deception (Colnerud \& Rosander, 2009).

According to the Swedish statistics from 2010, even though there are more female (59 \%) than male full-time students, only $42 \%$ of the students with disciplinary sentences are female, identifying that females are less prevalent in disciplinary matters. Female students also deny academic dishonesty more than male students which could point to a possibly higher false conviction rate or that they are given lighter sentences due to their gender. Possible other explanations include: women are less prone to academic dishonesty, are involved with lesser infractions that do not result in discipline, or that their acts were unintentional. This last reason concurs with other studies (for example Awdry \& Sarre, 2013) where females reported that their plagiarism was unintentional compared to male students who said they had intentionally plagiarized their work ( $7 \%$ versus $1 \%$ of females). Other suggested explanations can be found in studies on gender difference in cognitive moral development (Gilligan 1982; Kohlberg 1973) and motivation/intentions related to unethical behavior (Colnerud and Rosander 2009; Tibbetts 1999; White 1999).

We saw no trend for gender bias in the penalty severity for academic dishonesty (warnings or suspensions). In some universities female students have a higher ratio and in other universities male students have a higher ratio. This could point to a lack of 
gender bias or could be attributed to environment conditions and mitigating circumstances that Swedish disciplinary boards are obliged to take into consideration (e.g., information given by teacher, length of study time, etc.) when deciding on disciplinary actions. The observed lack of trend in gender bias and the penalty severity for academic dishonesty is particularly interesting since it has been identified that women tend to receive less severe penalties for crimes than men do, when comparing the same crime (Ahola et al. 2009; Rodriguez et al. 2006). Based on a criminology perspective, one could expect to find gender bias concerning the penalty severity for academic dishonesty, where female students would receive less severe penalties than male students. However, based on this study this could not be generalized to female students implicated for academic dishonesty.

Careful scrutiny of the disciplinary incidents revealed a couple of interesting cases. A female and a male student were convicted by the disciplinary board for the same dishonest behavior (using course summary notes prepared by fellow students as unauthorized help during a home exam). Here the male student was not given any penalty but the female student was suspended, even though nothing in the process that we analyzed suggested that the female's infraction warranted a harder sentence than the male's. In another case, a female student was found guilty of plagiarism and sentenced to two weeks suspension in July. In comparison to the average suspension time for plagiarism (HSV 2006) this is a comparatively short time period. These are interesting cases to consider for their implications of gender bias, however it is too small a number to draw anything conclusive.

\section{Conclusion}

The question addressed in this study is: Do gender differences exist with respect to conviction of students for academic dishonesty? To answer this question we conducted an analysis of data from the SNAHE and from several Swedish universities from 2010.

Based on statistics from 2010 and self-reports on academic dishonesty behavior, female students are less prevalent in disciplinary matters, which is in agreement with many of the previous investigations on disciplinary matters. Moreover, we find no systematic gender bias in the severity of penalties (warnings or suspensions). Finally, our categorization of statements from sentenced students indicates that female students do not admit to academic dishonesty to the same extent that male students do. This could have many possible meanings such as they have been falsely convicted, that they deliberately lied when questioned about their behavior or that they were unaware that they were being dishonest and thereby it was not a deliberate act.

In this study it appears that the classification of student supersedes gender classification when assigning a discipline for academic dishonesty and that all students, male and female are judged based on the severity of the infraction regardless of gender. When compared to criminal sentencing, the male gendered norms of care-taker and protector that have been suggested to bias the decision-making process towards greater leniency for women, was not apparent when applied to academic disciplinary action.

As a future outlook, it would be interesting to do a more in-depth analysis of how gendered societal constructs in different cultures influence faculty decision-making for disciplining academic misconduct. It would also be interesting to further explore the 
correlation between academic and workplace dishonesty to identify how academic dishonesty trends correlate with workplace integrity as students transition from university to the workplace. Last but not least, it would certainly be of interest for universities to include in their discussions the more subjective aspects of the decision-making process (e.g., gender and ethnic bias) when developing policies and procedures for academic misconduct.

\section{Competing interests}

The authors declare that they have no competing interests.

\section{Authors' contributions}

JJ initiated the investigation and collected the data. JJ and HW discussed and interpreted the results. Both authors jointly drafted the manuscript with HW taking the lead role. Both authors read and approved the final manuscript.

\section{Acknowledgments}

We would like to thank Anna Berghe for her engagement and interest during the start-up phase of this project. Also, we thank Jessica Bolinsson, Alexandru Panican, Marie Bergström, and Torgny Roxå for valuable discussions and feedback. Bob Mickus is greatly acknowledged for the information he provided on the US process of disciplinary protocols.

\section{Author details}

${ }^{1}$ Urban Studies Department and Centre for Work Life and Evaluation Studies (CTA), Malmö University, 20506 Malmö, Sweden. ${ }^{2}$ Solid State Physics and the Nanometer Structure Consortium, Lund University, Box 118, SE-22100 Lund, Sweden.

Received: 25 August 2014 Accepted: 1 May 2015

Published online: 01 August 2015

\section{References}

Ahola AS, Christianson SA, Hellstrom A (2009) Justice needs a blindfold: effects of gender and attractiveness on prison sentences and attributions of personal characteristics in a judicial process. Psychiatry Psychol Law 16(Supplement):S90-S100

Ameen EC, Guffey DM, McMillan JJ (1996) Gender differences in determining the ethical sensitivity of future accounting professionals. J Bus Ethics 15(5):591-597

Athanasou JA, Olasehinde O (2002) Male and female differences in self-report cheating, Practical assessment, research \& evaluation, 8, article 5

Awdry R, Sarre R (2013) An investigation into plagiarism motivations and prevention techniques: Can they be appropriately aligned? Int J Educ Integr 9(2):35-49

Colnerud G, Rosander M (2009) Academic dishonesty, ethical norms and learning. Assess Eval High Educ 34(5):505-517

Edgren S, Walters S (2006) Distance learning exchange: academic dishonesty in the 21st century. J Contin High Educ 54(2):56-59

Gibson CL, Khey D, Schreck CJ (2008) Gender, Internal control, and Academic dishonesty: Investigating mediating and differential effects. J Crim Just Educ 19(1):2-18

Gilligan C (1982) In a different voice: psychological theory and Women's development. Harvard University Press, Cambridge, Mass

Glendinning I (2013) Comparison of policies for academic integrity in higher education across the European union. Impact for policies of plageriarism in higher education across Europe. IPPHEAE project consortium. European commission, Coventry University, UK

Glendinning I (2014) Responses to student plagiarism in higher education across Europe. Intl J Educ Int 10(1):4-20

HSV (2005) Disciplinärenden 2004 vid högskolor och universitet med statligt huvudmannaskap, [Disciplin cases 2004 at university colleges and universities with state leadership]. Swedish National Agency for Higher Education (Högskoleverket), Stockholm, Sweden, p 28 R

HSV (2006) Disciplinärenden 2005 vid högskolor och universitet med statligt huvudmannaskap och tre av de större enskilda utbildningsanordnarna, [Disciplin cases 2004 at university colleges and universities with state leadership and three of the larger autonomous educational institutes]. Swedish National Agency for Higher Education (Högskoleverket), Stockholm, Sweden, p 15 R

HSV (2011) Disciplinära åtgärder mot studenter, [Disciplinary action against students]. Swedish National Agency for Higher Education (Högskoleverket), Stockholm, Sweden, p 10 R

Hughes JM, McCabe DL (2006) Year? Understanding academic misconduct. Can J High Educ 36(1):49-63

Kohlberg $L$ (1973) The claim to moral adequacy of a highest stage of moral judgment. J Philos 70(18):630-646

Leming JS (1980) Cheating behavior, subject variables, and components of the internal-external scale under high and Low-risk conditions. J Educ Res 74(2):83-87

Magnus JR, Polterovich VM, Danilov DL, Savvateev AV (2002) Tolerance of cheating: an analysis across countries. J Econ Educ 33(2):125-135

McCabe DL (2005) Cheating among college and university students: a north American perspective. Int J Educ Integr 1(1):1-11

Nonis S, Swift CO (2001) An examination of the relationship between academic dishonesty and workplace dishonesty: a multicampus investigation. J Educ Bus 77:69-71

Parameswaran A (2007) Student dishonesty and faculty responsibility. Teach High Educ 12(2):263-274 
Robinson-Zañartu C, Peña ED, Cook-Morales V, Peña AM, Afshani R, Nguyen L (2005) Academic crime and punishment: faculty members' perceptions of and responses to plagiarism. Sch Psychol Q 20(3):318

Rodriguez SF, Curry TR, Lee G (2006) Gender differences in criminal sentencing: Do effects vary across violent, property, and drug offenses? Soc Sci Q 87(2):318-339

Sprague J, Massoni K (2005) Student evaluations and gendered expectations: what we can't count can hurt us. Sex Roles 53(11-12):779-793

Steffensmeier D, Hebert C (1999) Women and men policymakers: does the judge's gender affect the sentencing of criminal defendants? Soc Forces 77(3):1163-1196

Tibbetts SG (1999) Differences between women and men regarding decisions to commit test cheating. Res High Educ 40(3):323-342

Tittle CR, Rowe AR (1973) Moral appeal, sanction threat, and deviance - experimental test. Soc Probl 20(4):488-498

Trost K (2009) Psst, have you ever cheated? a study of academic dishonesty in Sweden. Assess Eval High Educ 34:367-376

UKÄ (2013) Disciplinärenden 2012 vid universitet och högskolor, [Disciplin cases 2012 at universities and university colleges]. Swedish higher education authority (Universitetskanslerämbetet), Stockholm, Sweden, p 6

UKÄ (2014) Disciplinärenden 2013 vid universitet och högskolor, [Disciplin cases 2013 at universities and university colleges]. Swedish higher education authority (Universitetskanslerämbetet), Stockholm, Sweden, p 3

White RD (1999) Are women more ethical? recent findings on the effects of gender upon moral development, Journal of public administration research and theory 9, no. 3., pp 459-471

Whitley BE, Nelson AB, Jones CJ (1999) Gender differences in cheating attitudes and classroom cheating behavior: a meta-analysis. Sex Roles 41(9-10):657-680

Submit your manuscript to a SpringerOpen ${ }^{\circ}$ journal and benefit from:

- Convenient online submission

- Rigorous peer review

- Immediate publication on acceptance

- Open access: articles freely available online

- High visibility within the field

- Retaining the copyright to your article

Submit your next manuscript at $>$ springeropen.com 